
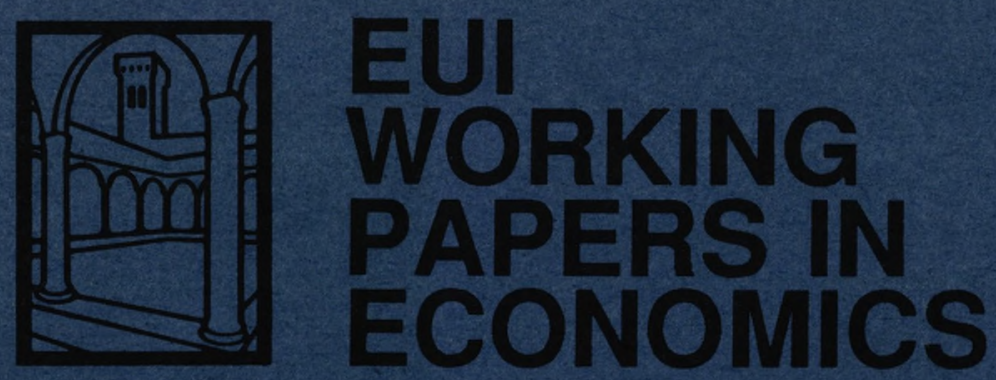

EUI Working Paper ECO No. 90/19

Money Metric Measures

of Individual and Social Welfare

Allowing for Environmental Externalities

Peter J. Hammond 
European University Library

|| ||| ||||||||||||||||||||| ||||||||||||||||||||||||||||||||||

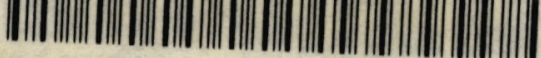

\begin{tabular}{l}
$3000100115477 \quad 4$ \\
\hline
\end{tabular}

Please note

As from January 1990 the EUI Working Paper Series is divided into six sub-series, each sub-series will be numbered individually (e.g. EUI Working Paper LAW No 90/1). 


\section{EUROPEAN UNIVERSITY INSTITUTE, FLORENCE}

ECONOMICS DEPARTMENT

EUI Working Paper ECO No. 90/19

Money Metric Measures

of Individual and Social Welfare

Allowing for Environmental Externalities

PETER J. HAMMOND

BADIA FIESOLANA, SAN DOMENICO (FI) 
All rights reserved.

No part of this paper may be reproduced in any form without permission of the author.

(C) Peter J. Hammond

Printed in Italy in October 1990

European University Institute

Badia Fiesolana

I-50016 San Domenico (FI)

Italy 


\title{
Money Metric Measures of Individual and Social Welfare Allowing for Environmental Externalities
}

\author{
Peter J. Hammond, Department of Economics,
} European University Institute, Badia Fiesolana, I-50016 S. Domenico (FI), Italy and Stanford University, CA 94305-6072, U.S.A.

Preliminary Version: September 1990; based on the presentation to the Fifth Karlsruhe Seminar, on "Models and Measurement of Welfare and Inequality".

\begin{abstract}
Even with environmental externalities, money metric measures of individual welfare can often be constructed by methods similar to those of Vartia (1983), provided that individual's willingness to pay functions are known. Satisfactory money metric measures of social welfare are harder, however. A new uniform money metric measure is proposed, based on the uniform poll subsidy (or tax) to all individuals which produces the same gain (or loss) in social welfare. Finally, problems with the definition of such measures when faced with "environmental catastrophe" are discussed.
\end{abstract}




\section{Introduction}

How large are the welfare losses caused by various forms of environmental degradation? This is becoming one of the pressing questions of our time. Some argue that the losses are not very large, and certainly too small to justify the kind of immensely costly measures which seem to be required if the environment is to be greatly improved, or even if the rate of deterioration is to be significantly slowed. Others argue the reverse. This paper will not settle such arguments but will lay out some of the principles involved in measuring such welfare losses.

In fact the problem of determining the welfare losses or gains caused by changes in the environment is just an instance of the general problem of measuring welfare change. There are, however, two distinctions of some importance. First, most welfare measures in the past have been constructed on the assumption that consumers take prices as given, and then adjust quantities optimally in order to maximize their own welfare. With environmental quality, however, it is usually the case that consumers as individuals have little influence. Environmental quality should therefore be treated as exogenous. Fortunately, it seems easy to adapt standard procedures to cover this case - provided, at least, that enough is known about each consumer's marginal willingness to pay for quality improvements.

There is, however, a second distinction which does make welfare measurement much harder. This is when the quality of the environment deteriorates so badly that the usual money metric measures like equivalent variation become undefined. A similar phenomenon was first noticed by Jones-Lee $(1974,1976)$ in connection with large increases in the probability of death. Individuals may be willing to part with all their possessions rather than face too large a probability of dying suddenly. For similar reasons, money metric measures may be ill equipped to deal with certain kinds of environmental catastrophe.

In addition, while it is true that the principles of constructing money metric measures of welfare change for individuals are gradually becoming well understood, similar measures for society as a whole have been far less satisfactory. Too 
many "surplus economists" in the past have simply added up equivalent variation over all individuals, treating the monetary gain which a billionaire enjoys from a slight increase in the quality of the wine he drinks on a par with that of a young child from a poor family who receives life-saving medical treatment. Alternative measures with more reasonable welfare weights have been proposed, of course, but suffer from other disadvantages. For example, the "social expenditure function" due to Pollak (1981) - which has also been used by Jorgenson and Slesnick (1989, 1990) and by Jorgenson (1989) - relies upon non-local information even for small changes in the economic allocation. The alternative approach based on fixed welfare weights which I proposed in Hammond $(1984,1988)$ seems neither practical nor easy to interpret. Accordingly, Section 3 below proposes a new measure of uniform equivalent variation. This is the uniform poll tax or subsidy which would generate the same change in social welfare. Since uniform poll subsidies or taxes do seem feasible (if undesirable) policy instruments, there is a sense in which this measure relates to an alternative policy change which could actually be carried out. Also, unlike the social expenditure function, for small changes the uniform equivalent variation will depend only on local information such as price elasticities of demand and relative marginal utilities of income.

The layout of the paper is as follows. Section 2 shows how to construct money metric measures of individual welfare and of welfare change by adapting the methods devised by Hausman (1981) for dealing with a single price change, and by Vartia (1983) for the more general case when all prices can change. Section 3 applies similar methods to the problem of measuring social welfare and welfare change. Section 4 contains concluding remarks. 


\section{Individual Welfare}

\subsection{Traded and Non-traded Goods}

It will be assumed that there is a finite set $G$ of traded goods, whose prices the consumer takes as exogenous, and a disjoint finite set $H$ of non-traded goods, whose quantities the consumer takes as exogenous.

The traded goods will typically be ordinary physical goods which the consumer is free to buy and sell on competitive markets. In the past the environment has usually been (imperfectly) ameliorated by means of quantitative controls on those activities of each individual and each firm which create pollution or other kinds of externalities. Many economists, however, are now recommending that environmental quality should be assured instead by issuing only a limited number of licences or permits to create certain types of pollution, and only in limited amounts. Many also recommend trying to improve the efficiency of the allocation of pollution rights by allowing such permits to be bought and sold on an open competitive market. To the extent that there are such tradeable licences to cause pollution, they should also be included among the set $G$ of traded goods.

Non-traded goods in the set $H$, on the other hand, are intended to include everything whose allocation to the consumer is determined by quantitative controls, or by no controls at all. Some components of $H$ will therefore describe environmental quality, others public goods, and yet others any rationing which the consumer faces.

Quantities of these two types of good will be denoted by the two vectors $x \in \Re^{G}$ and $z \in \Re^{H}$ respectively. For traded goods, including those subject to rationing constraints, these quantities are to be thought of as indicating net trades - i.e., demands minus supplies. For environmental quality levels beyond the consumer's control, any unambiguous ordinal measure is acceptable for each component of $z$. 


\subsection{An Ordinal Utility Function}

It will also be assumed that the consumer has a well-defined and unique ordinal equivalence class of real-valued utility functions $U(x, z)$. In what follows, $U$ will always stand for some particular utility function of this class - this is just a more precise way of saying that $U$ is an ordinal utility function. The domain of $U$ is taken to be a set $F \subset \Re^{G} \times \Re^{H}$ of individually feasible pairs $(x, z)$. Apart from the usual endowment and physical feasibility constraints, $F$ should also allow for any domestic production possibilities which the consumer may be able to undertake. It should also embody legal constraints such as the obligation of having a pollution licence, etc.

For fairly obvious technical reasons, it will be assumed that both the consumer's feasible set $F$ and preferences over $F$ allow some utility representation $U(x, z)$ satisfying the following standard assumptions:

(A.1) $F$ is a closed and convex set in $\Re^{G} \times \Re^{H}$;

(A.2) the section $F_{X}(z) \subset \Re^{G}$ of $F$ defined by $F_{X}(z)=\left\{x \in \Re^{G} \mid(x, z) \in F\right\}-$ i.e., the set of net trade vectors $x$ which are individually feasible in combination with $x-$ is bounded below in the sense that there exists some $\underline{x}(z) \in \Re^{G}$ with the property that $(x, z) \in F \Longrightarrow x \geqq \underline{x}(z)$;

(A.3) the function $U(x, z)$ on $F$ is continuously differentiable;

(A.4) as a function of the net trade vector $x$ alone, the function $U(x, z)$ is strictly quasi-concave;

(A.5) the partial gradient vector $U_{x}^{\prime}$ of $U$ with respect to $x$ is semi-positive (i.e., has no negative components and at least one positive component) at every point of $F$.

Note in particular that no presumption has been made regarding how $U(x, z)$ changes in response to variations in $z$. Indeed, nothing has even been assumed about the signs of the various components of the partial gradient vector $U_{z}^{\prime}$ of $U$ with respect to $z$. After all, what one consumer regards as a beneficial change in one particular exogenous quantity may be quite damaging to somebody else. 
Of course, the ordinal equivalence class of utility functions $U$ is assumed to be unknown. If it were known, then the problem of measuring "economic" welfare - under the important value judgement that what the consumer prefers is indeed better - would already have been solved. Instead, the problem considered here is precisely to construct a "money-metric" ordinal representation of the preferences which are revealed by the consumer's own behaviour.

\subsection{Prices and Marginal Willingness to Pay}

Obviously, the construction of a money-metric measure of individual welfare will also require the use of price data. For traded goods in the set $G$, it is assumed as usual that there is an observable exogenous price vector $p \in \Re_{+}^{G} \backslash\{0\}$ of nonnegative prices which are not all zero. The corresponding income level of the consumer is $m=p \cdot x$. This must be "unearned income" from dividends and income transfers because all earned income from selling (traded) labour services or other goods is already accounted for in one or more negative terms of the sum $p \cdot x=\sum_{g \in G} p_{g} x_{g}$.

For all non-traded goods in the set $H$ as well, it is assumed that there is a known price vector $w \in \Re^{H}$. Here each component $w_{h}$ of $w$ represents the consumer's marginal willingness to pay to have the exogenous quantity $z_{h}$ changed. In the case of any component $h$ representing a form of environmental quality or some public good, the interpretation of $w_{h}$ is clear and familiar. For any component $h$ representing a rationing constraint, $w_{h}$ represents the shadow price of relaxing the corresponding constraint. A crucial assumption which cannot be avoided here is that some procedure has also been devised for observing each consumer's "marginal willingness to pay vector" $w \in \Re^{H}$. This is a far from innocuous assumption, of course, but without it one would have to embark on a lengthy detour to discuss how to estimate $w$ by indirect methods. Indeed, in the absence of any information whatsoever about $w$, the task of trying to estimate an individual's direct welfare gains and losses from environmental change is clearly impossible. For example, if not even the sign of $w_{h}$ is known, one cannot even 
tell whether an increase in $z_{h}$ will benefit or harm the consumer. So, without information about $w$, at most those indirect gains and losses which arise because new policies only affect the allocation of traded goods to the consumer could be measured. Actually, such indirect gains and losses are often very important. They arise, for instance, whenever a firm is affected by a policy change. Finally, note that even if externality permits are traded, the observed prices can only tell us how much each individual is willing to pay for the right to create each such externality; they cannot tell us the marginal benefits from having everybody create less of the externality in the aggregate.

\subsection{Implications of Utility Maximization}

As usual, it will be assumed that the consumer chooses the endogenous net trade vector $x \in \Re^{G}$ in order to maximize the utility function $U(x, z)$ over the individually feasible set $F$, subject to the budget constraint $p \cdot x \leq m$. Because of assumptions (A.1) and (A.4), the utility maximizing net vector will always be unique, so there is a single-valued net demand function $x(p, m ; z)$ whose arguments include the exogenous quantity vector $z$, along with the usual price vector $p$ and income level $m$. Let $v(p, m ; z):=U(x(p, m ; z), z)$ denote the consumer's indirect utility function. Obviously

$$
\left.\begin{array}{l}
x(p, m ; z)=\arg \\
v(p, m ; z)=
\end{array}\right\} \max _{x}\{U(x, z) \mid x \in F ; p \cdot x \leq m\} .
$$

Given our assumptions, the indirect utility function $v(p, m ; z)$ will be differentiable as a function of $p$ and $m$ together, except perhaps when $x(p, m ; z)$ is on the boundary of the conditionally feasible set $F_{X}(z)$. At least it will always be continuous as a function of $m$ alone. The consumer's marginal utility of income $\lambda(p, m ; z)$ is defined in the usual way as $\frac{\partial}{\partial m} v(p, m ; z)$ or $v_{m}^{\prime}(p, m ; z)$. Because of assumption (A.5), this must be positive. The well known Roy's identity can then be expressed in the form

$$
v_{p}^{\prime}(p, m ; z)=-\lambda(p, m ; z) x(p, m ; z)
$$


where $v_{p}^{\prime}(p, m ; z)$ denotes the partial gradient vector of $v$ with respect to $p$.

On the other hand $w$, the consumer's marginal willingness to pay for changes in the exogenous quantity vector $z$, must be a function $w(p, m ; z)$ satisfying

$$
v_{z}^{\prime}(p, m ; z)=U_{z}^{\prime}(x(p, m ; z), z)=\lambda(p, m ; z) w(p, m ; z) .
$$

\subsection{The Money Metric Utility Function}

In order to construct money metric measures of welfare and of welfare change, it will be necessary to keep fixed both a reference price vector $p^{R} \in \Re_{+}^{G}$ and a reference exogenous quantity vector $z^{R} \in \Re^{H}$. Then the money metric direct utility function $\phi(x, z)$ is defined implicitly as the solution to the equation

$$
v\left(p^{R}, \phi(x, z) ; z^{R}\right)=U(x, z) .
$$

In other words, $\phi(x, z)$ is the level of unearned income which, if made available to the consumer when facing the reference price vector $p^{R}$ and the reference exogenous quantity vector $z^{R}$, and if spent optimally on an appropriate utility maximizing net trade vector, would make the consumer just as well off as at $(x, z)$. Although $p^{R}$ and $z^{R}$ are really additional arguments of the function $\phi(x, z)$, they will be suppressed because they should always be held constant when constructing any money metric measure of welfare. Note that, because the marginal utility of income $\lambda\left(p^{R}, \phi(x, z) ; z^{R}\right)$ is always positive, $\phi(x, z)$ does increase strictly as $U(x, z)$ increases.

The money metric indirect utility function $\psi(p, m ; z)$ is defined similarly as the solution to the equation

$$
v\left(p^{R}, \psi(p, m ; z) ; z^{R}\right)=v(p, m ; z) .
$$

It has the property that $\psi(p, m ; z)=\max _{x}\{\phi(x, z) \mid x \in F ; p \cdot x \leq m\}$ because of (1) above.

When the exogenous variables $(p, z)$ assume their reference values $\left(p^{R}, z^{R}\right)$, it must be true that $\psi\left(p^{R}, m ; z^{R}\right) \equiv m-$ i.e., the money metric measure of utility 
becomes equal to actual unearned income. This shows, moreover, the money metric utility function has been constructed so that the marginal utility of income for the reference exogenous price and quantity vector is always equal to one. ${ }^{1}$

\subsection{The Compensating, Equivalent, and General Variation}

Measures of welfare change are concerned with the effect on the consumer of a change in exogenous variables. To this end, consider a change which takes the exogenous variables $(p, m, z)$ from their initial values $\left(p^{0}, m^{0}, z^{0}\right)$ to some new final values $\left(p^{1}, m^{1}, z^{1}\right)$. Given the particular reference price and quantity vectors $\left(p^{R}, z^{R}\right)$, a corresponding measure of welfare change is the general variation

$$
\psi\left(p^{1}, m^{1} ; z^{1}\right)-\psi\left(p^{0}, m^{0} ; z^{0}\right)
$$

in money metric utility.

Two particular measures of variation have received much attention in the literature, following Hicks $(1939,1940,1981)$. The first is the compensating variation. This arises when $\left(p^{R}, z^{R}\right)=\left(p^{1}, z^{1}\right)$, so the final values of the exogenous prices and quantities are taken as reference values. Then (5) implies that $\psi\left(p^{1}, m^{1} ; z^{1}\right)=\psi\left(p^{R}, m^{1} ; z^{R}\right)=m^{1}$, and so the measure of welfare change (6) becomes CV $:=m^{1}-\psi\left(p^{0}, m^{0} ; z^{0}\right)$. Since (5) also implies that $\psi\left(p^{0}, m^{0} ; z^{0}\right)=$ $m^{1}-\mathrm{CV}$ must satisfy $v\left(p^{1}, m^{1}-\mathrm{CV} ; z^{1}\right)=v\left(p^{0}, m^{0} ; z^{0}\right)$, the measure CV represents the total amount which the consumer is willing to pay to make the move from $\left(p^{0}, m^{0}, z^{0}\right)$ to $\left(p^{1}, m^{1}, z^{1}\right)$. Given a fixed final situation $\left(p^{1}, m^{1}, z^{1}\right)$, this measure of compensating variation increases as the status quo $\left(p^{0}, m^{0}, z^{0}\right)$ becomes worse. Nothing can be said, however, about whether it increases or decreases as the (probably more interesting) final situation changes.

The second particular measure is the equivalent variation, which arises when $\left(p^{R}, z^{R}\right)=\left(p^{0}, z^{0}\right)$, so the initial values of the exogenous prices and quantities

${ }^{1}$ It is usual, of course, to define money metric utility in terms of the expenditure function. This approach is usually equivalent to that adopted above, but may be inaccurate when utility maximizing demands lie on the boundary of the feasible set. This, and also the closer parallels with what follows later when I discuss money metric social welfare measures, are my reasons for using indirect utility rather than expenditure functions in this paper. 
are taken as reference values. Then $\psi\left(p^{0}, m^{0} ; z^{0}\right)=\psi\left(p^{R}, m^{0} ; z^{R}\right)=m^{0}$ because of (5). So the measure of welfare change (6) becomes $\mathrm{EV}:=\psi\left(p^{1}, m^{1} ; z^{1}\right)-m^{0}$. In contrast to the compensating variation, the equivalent variation is higher for better changes from an existing status quo, so can itself be used as a welfare indicator. Since (5) implies that $\psi\left(p^{1}, m^{1} ; z^{1}\right)=m^{0}+\mathrm{EV}$ must satisfy the equation $v\left(p^{0}, m^{0}+\mathrm{EV} ; z^{0}\right)=v\left(p^{1}, m^{1} ; z^{1}\right)$, the measure EV represents the total amount which the consumer is willing to be paid in order not to make the move from $\left(p^{0}, m^{0}, z^{0}\right)$ to $\left(p^{1}, m^{1}, z^{1}\right)$.

\subsection{Small Changes}

The problem to be considered next is how to calculate such measures of variation when the indirect utility function is not known. It will be assumed that one knows instead only the vector demand function $x(p, m ; z)$ for those goods whose prices are exogenous and whose quantities are endogenous, as well as the vector willingness to pay function $w(p, m ; z)$ for those goods whose quantities are exogenous and whose prices are endogenous.

The effect of a small change upon the money metric measure of individual welfare can be found by taking the total differential of (5), which is

$$
\begin{aligned}
v_{m}^{\prime}\left(p^{R}, \psi(p, m ; z) ; z^{R}\right) d \psi & =d p \cdot v_{p}^{\prime}(p, m ; z)+v_{m}^{\prime}(p, m ; z) d m+v_{z}^{\prime}(p, m ; z) \cdot d z \\
& =v_{m}^{\prime}(p, m ; z)[d m-d p \cdot x(p, m ; z)+w(p, m ; z) \cdot d z]
\end{aligned}
$$

where the second equation follows from Roy's identity. So

$$
d \psi=\frac{v_{m}^{\prime}(p, m ; z)}{v_{m}^{\prime}\left(p^{R}, \psi(p, m ; z) ; z^{R}\right)}[d m-d p \cdot x(p, m ; z)+w(p, m ; z) d z]
$$

In the special case when $(p, z)$ is the reference point $\left(p^{R}, z^{R}\right)$ and so $\psi(p, m ; z)$ becomes equal to $m$, this reduces to the familiar form

$$
d \psi=d m-d p \cdot x(p, m ; z)+w(p, m ; z) \cdot d z .
$$




\subsection{A Path Differential Equation}

In order to be able to compute the effect of any larger change, it is obviously sufficient to know how to find the money metric measure of utility $\psi(\bar{p}, \bar{m} ; \bar{z})$ for any point $(\bar{p}, \bar{m}, \bar{z})$, and with respect to an arbitrary reference point $\left(p^{R}, z^{R}\right)$. To this end, let $(p(t), z(t))(0 \leq t \leq 1)$ be any continuously differentiable path, parametrized by the real variable $t$, whose endpoints are respectively $(p(0), z(0))=$ $(\bar{p}, \bar{z})$ and $(p(1), z(1))=\left(p^{R}, z^{R}\right)$. For example, one could take the line segment joining $(\bar{p}, \bar{z})$ to $\left(p^{R}, z^{R}\right)$, with $p(t)=\bar{p}+t\left(p^{R}-\bar{p}\right)$ and $z(t)=\bar{z}+t\left(z^{R}-\bar{z}\right)$. But other paths could be much more convenient instead. Note that the chosen path starts at $(\bar{p}, \bar{z})$, the target point where the money metric is to be evaluated, and then comes back to the reference point $\left(p^{R}, z^{R}\right)$.

Along such a path, we will now construct an income compensation function $m(t)$ with the property that

$$
v(p(t), m(t) ; z(t))=v(\bar{p}, \bar{m} ; \bar{z})
$$

whenever $0 \leq t \leq 1$. In other words, the path $(p(t), m(t), z(t))(0 \leq t \leq 1)$ will be part of one of the consumer's indifference curves -- or, more exactly, a level surface of the indirect utility function. Obviously $m(0)=\bar{m}$ when $t=0$. At the other end of the path, when $t=1$ and so $(p(t), z(t))=\left(p^{R}, z^{R}\right)$, one will have $v\left(p^{R}, m(1) ; z^{R}\right)=v(\bar{p}, \bar{m} ; \bar{z})$. This implies that $m(1)=\psi(\bar{p}, \bar{m} ; \bar{z})$, and so $m(1)$ is the required money metric measure of utility.

The construction of $m(t)$ requires solving an ordinary differential equation. For differentiating (10) totally with respect to $t$ gives

$$
\begin{aligned}
0=\frac{d}{d t} v(p(t), m(t) ; z(t)) & =\dot{p} \cdot v_{p}^{\prime}+v_{m}^{\prime} \dot{m}+v_{z}^{\prime} \cdot \dot{z} \\
& =\lambda[-\dot{p} \cdot x(p, m ; z)+\dot{m}+w(p, m ; z) \cdot \dot{z}],
\end{aligned}
$$

where, of course, $\dot{p}, \dot{m}$ and $\dot{z}$ denote derivatives with respect to $t$. Since (A.5) implies that $\lambda$ is always positive, (11) reduces to the ordinary differential equation

$$
\dot{m}=\dot{p} \cdot x(p, m ; z)-w(p, m ; z) \cdot \dot{z}
$$


in $m(t)$, with initial condition $m(0)=\bar{m}$, of course.

\subsection{Integrability and Path Independence}

Suppose that the demand and willingness to pay functions are derived from preferences satisfying assumptions (A.1-A.5) above. Then equation (12) must give a unique solution for $m(1)$ which is independent of how the path $(p(t), z(t))$ $(0 \leq t \leq 1)$ from $(\bar{p}, \bar{z})$ to $\left(p^{R}, z^{R}\right)$ is chosen. In fact, the only possible solution for $m(1)$ is precisely the desired money metric utility level $\psi(\bar{p}, \bar{m} ; \bar{z})$.

It is more interesting, however, to know what conditions the demand and willingness to pay functions $x(p, m ; z)$ and $w(p, m ; z)$ must satisfy in order to ensure that they do correspond to a preference ordering for the consumer. As is well known, the net demand function $x(p, m ; z)$ should satisfy the budget condition (B) that $p \cdot x(p, m ; z)=m$. In addition, both functions $x(p, m ; z)$ and $w(p, m ; z)$ should be homogeneous of degree zero as $p$ and $m$ vary together, in the sense that

$$
x(\alpha p, \alpha m ; z)=x(p, m ; z) ; \quad w(\alpha p, \alpha m ; z)=w(p, m ; z)
$$

for every positive scalar $\alpha$. The other condition that is usually invoked, in order to ensure that the differential equation (12) does have a solution, is a form of Lipschitz condition. This requires the income derivatives $x_{m}^{\prime}(p, m ; z)$ and $w_{m}^{\prime}(p, m ; z)$ to be bounded on any path along which one wants to solve (12). This will be true automatically whenever these income derivatives are actually continuous functions of $(p, m, z)$.

Of rather more interest are the appropriate versions of the familiar conditions requiring the Slutsky matrix to be both symmetric and negative semi-definite. To investigate this, notice first how (12) will have a unique and path independent solution for $m(t)$ along any path from $(\bar{p}, \bar{z})$ to the reference point $\left(p^{R}, z^{R}\right)$, with the initial condition $m(0)=\bar{m}$ always being satisfied, if and only if there exists a general income compensation function $m(p, z)$ which satisfies the more general version

$$
v(p, m(p, z) ; z)=v(\bar{p}, \bar{m} ; \bar{z})
$$


of (10). The usual integrability condition is that any possible solution to (13) should have a symmetric Hessian matrix

$$
\left(\begin{array}{ll}
m_{p p}^{\prime \prime} & m_{p z}^{\prime \prime} \\
m_{z p}^{\prime \prime} & m_{z z}^{\prime \prime}
\end{array}\right)
$$

of second order partial derivatives. But differentiating (13) partially with respect to the components of $p$ and of $z$ gives:

$$
\begin{gathered}
v_{p}^{\prime}(p, m(p, z) ; z)+v_{m}^{\prime}(p, m(p, z) ; z) m_{p}^{\prime}(p, z)=0 \\
v_{z}^{\prime}(p, m(p, z) ; z)+v_{m}^{\prime}(p, m(p, z) ; z) m_{z}^{\prime}(p, z)=0 .
\end{gathered}
$$

Using Roy's identity (2) and also (3) once again then implies that

$$
m_{p}^{\prime}(p, z)=x(p, m(p, z) ; z) ; \quad m_{z}^{\prime}(p, z)=-w(p, m(p, z) ; z) .
$$

In fact, these are really just familiar envelope results for compensated demand and willingness to pay functions. Differentiating (16) partially once more leads to the following equation for the partitioned Hessian matrix (14)

$$
\left(\begin{array}{cc}
m_{p p}^{\prime \prime} & m_{p z}^{\prime \prime} \\
m_{z p}^{\prime \prime} & m_{z z}^{\prime \prime}
\end{array}\right)=\left(\begin{array}{cc}
x_{p}^{\prime}+x_{m}^{\prime} x^{T} & x_{z}^{\prime}-x_{m}^{\prime} w^{T} \\
-w_{p}^{\prime}-w_{m}^{\prime} x^{T} & -w_{z}^{\prime}+w_{m}^{\prime} w^{T}
\end{array}\right)
$$

where ${ }^{T}$ denotes the transpose of a matrix. The convention that $w, x, w_{m}^{\prime}$ and $x_{m}^{\prime}$ are all column vectors has also been used. In terms of explicit second order partial derivatives, (17) can be written as

$$
\begin{aligned}
& \left(\begin{array}{cc}
{\left[\frac{\partial^{2} m}{\partial p_{g} \partial p_{g^{\prime}}}\right]_{g, g^{\prime} \in G}} & {\left[\frac{\partial^{2} m}{\partial p_{g} \partial z_{h}}\right]_{g \in G, h \in H}} \\
{\left[\frac{\partial^{2} m}{\partial z_{h} \partial p_{g}}\right]_{h \in H, g \in G}} & {\left[\frac{\partial^{2} m}{\partial z_{h} \partial z_{h^{\prime}}}\right]_{h, h^{\prime} \in H}}
\end{array}\right) \\
= & \left(\begin{array}{cc}
{\left[\frac{\partial x_{g}}{\partial p_{g^{\prime}}}+\frac{\partial x_{g}}{\partial m} x_{g^{\prime}}\right]_{g, g^{\prime} \in G}} & {\left[\frac{\partial x_{g}}{\partial z_{h}}-\frac{\partial x_{g}}{\partial m} w_{h}\right]_{g \in G, h \in H}} \\
{\left[-\frac{\partial w_{h}}{\partial p_{g}}-\frac{\partial w_{h}}{\partial m} x_{g}\right]_{h \in H, g \in G}} & {\left[-\frac{\partial w_{h}}{\partial z_{h^{\prime}}}+\frac{\partial w_{h}}{\partial m} w_{h^{\prime}}\right]_{h, h^{\prime} \in H}}
\end{array}\right),
\end{aligned}
$$

where all the partial derivatives of the generalized income compensation function $m$ are evaluated at $(p, z)$, and all those of the demand and willingness to pay functions are evaluated at $(p, m ; z)$. 
The upper left hand corner is the familiar Slutsky matrix. Utility maximization implies that this must not only be symmetric, but also negative semi-definite. All the rest of the matrix must be symmetric as well, though not necessarily negative semi-definite because no optimization with respect to either $w$ or $z$ is involved. This completes the specification of the relevant integrability conditions which are sufficient to ensure that the demand and willingness to pay functions do correspond to the solution of a utility maximization problem on the part of the consumer.

\subsection{Individual Catastrophes}

So far I have neglected one last important question. This is when the money metric utility function is well defined and when it is not. Recall how (5) defines $\psi(p, m ; z)$ as the (unique) value of $y$ which solves the equation

$$
v\left(p^{R}, y ; z^{R}\right)=v(p, m ; z)
$$

- assuming that such a $y$ exists. Now, in the case when all goods can be traded at exogenous prices and there are no exogenous quantities, (19) reduces to

$$
v\left(p^{R}, y\right)=v(p, m)
$$

In this case it has been customary to assume that the consumer's consumption set is the non-negative orthant $\Re_{+}^{G}$, and that there is a fixed endowment vector $e$. In this special case, the set $F$ of feasible net trades becomes equal to the vector difference $\Re_{+}^{G}-\{e\}$. So the indirect utility function is well defined for whenever $m \geq-p \cdot e$, and achieves a fixed minimum value of $\underline{v}:=v(p,-p \cdot e)=U(-e)$, no matter what $p$ may be. Then, however, $v\left(p^{R}, y\right)=\underline{v}$ when $y=-p^{R} \cdot e$. And $v\left(p^{R}, y\right) \geq v(p, m)$ whenever $y \geq p^{R} \cdot x(p, m)$ because a consumer who is faced with prices $p^{R}$ and income $y$ cannot be forced to do worse than have the net trade vector $x(p, m)$. Because the function $v\left(p^{R}, y\right)$ is continuous in $y$, its range must then include all the closed interval $\left[\underline{v}, v\left(p^{R}, p^{R} \cdot x(p, m)\right]\right.$ of the real line. So the point $v(p, m)$ in particular must lie in the range of $v\left(p^{R}, y\right)$, implying that (20) does have a solution. 
I shall now consider the more general case which occurs when some quantities may be exogenous to the consumer, or because the feasible set does not have the very special form $F=\Re_{+}^{G}-\{e\}$. To this end, define

$$
\underline{m}^{R}:=\min _{x}\left\{p^{R} \cdot x \mid\left(x, z^{R}\right) \in F\right\}
$$

as the minimum income level consistent with individual feasibility when the exogenous price and quantity vectors are at their reference levels. Let

$$
\underline{v}^{R}:=v\left(p^{R}, \underline{m}^{R} ; z^{R}\right)
$$

denote the corresponding minimum utility vector. Also, let

$$
\bar{v}^{R}:=\sup _{m}\left\{v\left(p^{R}, m ; z^{R}\right)\right\}
$$

be the corresponding supremum utility level, whose value could be $+\infty$. Then it is obvious that (19) has a well defined solution $\psi(p, m ; z)$ for all situations $(p, m, z)$ which satisfy the inequalities $\underline{v}^{R} \leq v(p, m ; z)<\bar{v}^{R}$. Outside this interval, however, money metric utility will not be well-defined for the particular reference price and quantity vectors $\left(p^{R}, z^{R}\right)$.

Consider first the case when the situation $(p, m, z)$ is so bad that $v(p, m ; z)<$ $\underline{v}^{R}$. Then, in the reference situation $\left(p^{R}, z^{R}\right)$, there is no unearned income level low enough to make the consumer as badly off as at $(p, m ; z)$ while still allowing individual feasibility. Some penalty other than a reduction in unearned income is required if utility is to be reduced this much. Compared to the reference situation, $(p, m, z)$ is an "individual catastrophe," in effect. No finite negative number $y$ is small enough to solve (19). No matter how much wealth $m^{R}$ he has in the situation $\left(p^{R}, m^{R}, z^{R}\right)$, the consumer would strictly prefer to give up all of it in order to avoid the change from $\left(p^{R}, m^{R}, z^{R}\right)$ to $(p, m, z)$. This could be because the change in the exogenous quantity variables from $z^{R}$ to $z$ constitutes some kind of personal disaster - for example, a sufficiently large increase in the probability of death or injury, as in Jones-Lee $(1974,1976)$. Such changes could also result 
from some kind of environmental catastrophe. Even without any exogenous quantity variables, however, the simpler equation (20) will still fail to have a solution if minimum subsistence at prices $p^{R}$ is sufficiently better for the consumer than minimum subsistence at prices $p$, and if income $m$ is sufficiently close to subsistence. Nevertheless, this possibility is certainly less plausible.

On the other hand, suppose the situation $(p, m, z)$ is so good that $v(p, m ; z) \geq$ $\underline{v}^{R}$. Then, in the reference situation, no (finite) unearned income level is high enough to make the consumer as well off as at $(p, m, z)$. Indeed, if $v(p, m ; z)>\bar{v}^{R}$, then not even $y=+\infty$ would be high enough, but some non-monetary reward would be required. If, for example, $(p, m, z)$ is a situation in the past when the consumer enjoyed normal health and reasonable prosperity, whereas the reference situation $\left(p^{R}, m^{R}, z^{R}\right)$ is one in which a personal disaster has already occurred, it is possible that no amount of money is ever enough to restore the consumer to his former level of well-being, and so compensate for the disastrous change from $z$ to $z^{R}$

What these possibilities illustrate is that money metrics are at best incomplete measures of welfare and of welfare change. Some alterations in individual circumstances can be so drastic that no finite sum of money can ever compensate, in which case the money metric is undefined. Applied economists should always take account of this possibility.

\section{Social Welfare and Uniform Variation}

\subsection{Additive Money Metric Utility}

This and succeeding sections will consider a finite set $I$ of individuals indicated by subscripts $i$. Boldface letters will denote profiles of vectors, one for each individual in society. For instance, $\mathbf{z}$ will denote the entire list $\left\langle z_{i}\right\rangle_{i \in I}$ of all the different exogenous quantity vectors $z_{i}$ faced by all the different individuals in society, $i \in I$. Similarly, $\mathbf{m}$ will denote the personal distribution of income in society, $\left\langle m_{i}\right\rangle_{i \in I}$. The problem then is to know how to construct appropriate money metric measures of social welfare for society as a whole. 
One such approach that has been used too much in the past is simply to add up all the different individuals' measures of money metric utility - i.e., one considers the sum $M(p, \mathbf{m} ; \mathbf{z})=\sum_{i \in I} \psi_{i}\left(p, m_{i} ; z_{i}\right)$. The reference situation $\left(p^{R}, \mathbf{z}^{R}\right)$ involves a combination of an exogenous price vector with specified levels of the exogenous quantitiy vector for each individual separately. Note the assumption that the exogenous price vector $p$ is the same for all individuals, as it will be if the economy has perfectly competitive markets for traded goods. Note too that in the reference situation itself, this additive money metric measure becomes $M\left(p^{R}, \mathbf{m} ; \mathbf{z}^{R}\right)=$ $\sum_{i \in I} \psi_{i}\left(p^{R}, m_{i} ; z_{i}^{R}\right)=\sum_{i \in I} m_{i}$, or just the total level of all unearned income, without any regard whatsoever for its distribution. This complete neglect of any concern for distributive justice explains why this measure has so little ethical appeal.

\subsection{Social Welfare Functions}

In order to go beyond crude measures like additive money metric utility, some more sophisticated value judgements and interpersonal comparisons of utility are required. Thus it will be assumed that there exists some direct social welfare function of the Paretian form

$$
W(\mathbf{x}, \mathbf{z}) \equiv \Omega\left(\left\langle U_{i}\left(x_{i}, z_{i}\right)\right\rangle_{i \in I}\right),
$$

where $\Omega$ is a strictly increasing function of the vector $\left\langle U_{i}\left(x_{i}, z_{i}\right)\right\rangle_{i \in I}$ of all the different individual utility levels. The corresponding indirect social welfare function, of course, must be

$$
V(p, \mathbf{m} ; \mathbf{z}) \equiv \Omega\left(\left\langle v_{i}\left(p, m_{i} ; z_{i}\right)\right\rangle_{i \in I}\right) .
$$




\subsection{Total Money Metric Utility}

To allow these rather more sophisticated ethical values, Jorgenson and Slesnick $(1989,1990)$ and Jorgenson (1989) have used an alternative method of money metric social welfare measurement. This is based on the idea behind Pollak's (1981) approach to constructing social cost of living indices. The method involves considering the total money income which, if distributed optimally, would yield the same level of social welfare. To define it formally, first let the indirect social welfare function of total income be given by

$$
V^{*}(p, M ; \mathbf{z}):=\max _{\mathbf{m}}\left\{V(p, \mathbf{m} ; \mathbf{z}) \mid \sum_{i \in I} m_{i} \leq M\right\}
$$

Thus $V^{*}(p, M ; \mathbf{z})$ represents the maximum level of social welfare that can be achieved by distributing the total income $M$ optimally among all individuals in society. Note that $V^{*}(p, M ; \mathbf{z})$ must always be an increasing function of $M$ because each individual's marginal utility of income $\lambda_{i}\left(p^{R}, m_{i} ; z_{i}^{R}\right)$ is always positive.

As in the case of single individuals, in order to construct money metric measures of social welfare and of social welfare change, a reference price vector $p^{R} \in \Re_{+}^{G}$ and a reference exogenous interpersonal profile of quantity vectors $\mathbf{z}^{\mathbf{R}}=\left\langle z_{i}^{R}\right\rangle_{i \in I} \in \Re^{H I}$ must both be kept fixed. Then the total money metric direct utility function $\Phi(\mathbf{x}, \mathbf{z})$ is defined implicitly as the solution to the equation

$$
V^{*}\left(p^{R}, \Phi(\mathbf{x}, \mathbf{z}) ; \mathbf{z}\right)=W(\mathbf{x}, \mathbf{z}) .
$$

In other words, $\Phi(\mathbf{x}, \mathbf{z})$ is the level of total unearned income which, if available for distribution between all consumers when society faces the reference price vector $p^{R}$ and the reference exogenous profile of quantity vectors $\mathbf{z}^{\mathbf{R}}$, and if distributed and then spent optimally on appropriate social welfare maximizing net trade vectors, would make society as a whole just as well off as at $(\mathbf{x}, \mathbf{z})$. Note that $\Phi(\mathbf{x}, \mathbf{z})$ does increase strictly as $W(\mathbf{x}, \mathbf{z})$ increases because, as shown in the previous paragraph, increses in total income $M$ can be used to generate increases in social welfare. 
The total money metric indirect utility function $\Psi(p, \mathbf{m} ; \mathbf{z})$ is defined similarly as the solution to the equation

$$
V^{*}\left(p^{R}, \Psi(p, \mathbf{m} ; \mathbf{z}) ; \mathbf{z}^{R}\right)=V(p, \mathbf{m} ; \mathbf{z})
$$

In the special case when the exogenous variables $(p, \mathbf{z})$ happen to assume their reference values $\left(p^{R}, \mathbf{z}^{\mathbf{R}}\right)$, it must be true that $\Psi\left(p^{R}, \mathbf{m} ; \mathbf{z}^{R}\right)$ becomes equal to the optimally distributed equivalent income - i.e., that level of total income which, if distributed optimally between the different individuals of society, would produce the same level of social welfare. The equivalent income $\Psi\left(p^{R}, \mathbf{m} ; \mathbf{z}^{R}\right)$ is only equal to $\sum_{i \in I} m_{i}$ when $\mathbf{m}$ happens to be an optimal distribution given $\left(p^{R}, \mathbf{z}^{\mathbf{R}}\right)$. Generally, of course, $\Psi\left(p^{R}, \mathbf{m} ; \mathbf{z}^{R}\right)$ is less than $\sum_{i \in I} m_{i}$, and the difference between the two is a total income measure of the social welfare loss due to distributive injustice. Of special note is the case considered by Atkinson (1970), in which an equal distribution of income is always optimal. Then $\Psi\left(p^{R}, \mathbf{m} ; \mathbf{z}^{R}\right)$ becomes none other than what Atkinson called the equally distributed equivalent income, and $\sum_{i \in I} m_{i}-\Psi\left(p^{R}, \mathbf{m} ; \mathbf{z}^{R}\right)$ becomes an income measure of the social welfare loss due to inequality.

Though such measures do accurately reflect the social welfare function, they will often be rather inconvenient and also hard to interpret. Suppose, for instance, that a policy change results in the economy moving from the original situation $s^{0}:=\left(p^{0}, \mathbf{m}^{0} ; \mathbf{z}^{0}\right)$ - which is a combination of a price vector for traded goods, an unearned income distribution, and profile of exogenous quantity vectors - to the new situation $s^{1}:=\left(p^{1}, \mathbf{m}^{1} ; \mathbf{z}^{1}\right)$. Suppose too that this change increases the above money metric measure of social welfare by precisely 100 ecus per head in a society whose population numbers 50 million. This means that the policy change has exactly the same welfare effect as the combination of the following three changes:

(i) with $p^{0}$ and $\mathbf{z}^{0}$ both fixed, the total income $M^{0}:=\sum_{i \in I} m_{i}^{0}$ which is available in the original situation $s^{0}$ is reduced to the optimally distributed income equivalent - say $\hat{M}^{0}$ - and then $\hat{M}^{0}$ is redistributed optimally by means 
of (first-best) lump-sum transfers in order to achieve a new distribution of income which generates exactly the same level of welfare as $s^{0}$;

(ii) additional income $\Delta M$ whose total is 5 billion ecus - equivalent to 100 ecus per head - is made available in order to bring the new total up to $\hat{M}^{0}+\Delta M$;

(iii) with $p^{1}$ and $z^{1}$ both fixed, the new total income $\hat{M}^{0}+\Delta M$ is redistributed optimally by means of lump-sum transfers, and the result must be a new distribution of income which generates exactly the same level of welfare as $s^{1}$.

Thus changes in social welfare are always calculated with reference to first-best optimal distributions of income. These are likely to be far from existing distributions, and also unattainable in practice - e.g., because of incentive constraints such as those considered in Hammond $(1979,1987)$ and Roberts (1984). Thus the figure of 100 ecus per head may be rather misleading, since it might be thought to indicate that the welfare effect is the same as if each individual received an extra 100 ecus in the original situation $s^{0}$, instead of in the welfare equivalent situation which only arises when total income has first been reduced to $\hat{M}^{0}$ and then optimally redistributed. Finally, the need to calculate the optimally distributed equivalent in each case is likely to be a major inconvenience. For one thing, even if the change from $s^{0}$ to $s^{1}$ is quite small, the two transitions from $s^{0}$ to the welfare equivalent situation with an optimal income distribution, and then from a different optimal income distribution back to $s^{1}$, are both likely to be large and difficult to calculate with much precision. For all these reasons the "uniform variation" measures to be presented below seem definitely more helpful.

\subsection{The Uniform Money Metric Measure of Social Welfare}

In order to construct the uniform money metric measures of social welfare and of social welfare change to be proposed here, not only must both some reference price vector $p^{R} \in \Re_{+}^{G}$ and some reference exogenous interpersonal profile of quantity vectors $\mathbf{z}^{\mathbf{R}}=\left\langle z_{i}^{R}\right\rangle_{i \in I} \in \Re^{H I}$ be kept fixed throughout; so also must a reference distribution $\mathbf{m}^{\mathbf{R}}=\left\langle m_{i}^{R}\right\rangle_{i \in I} \in \Re^{I}$ of unearned incomes. The new measure then involves considering that level of uniform poll subsidy which, if given to 
all individuals in the reference situation $\left(p^{R}, \mathbf{m}^{\mathbf{R}}, \mathbf{z}^{\mathbf{R}}\right)$, would yield the same level of social welfare.

Since direct money metric measures play no role in the rest of this paper, only the indirect uniform money metric social welfare function $\mu(p, \mathbf{m} ; \mathbf{z})$ will be defined. Formally, it is the (unique) solution to the equation

$$
V\left(p^{R}, \mathbf{m}^{R}+\mu(p, \mathbf{m} ; \mathbf{z}) \mathbf{1} ; \mathbf{z}^{R}\right)=V(p, \mathbf{m} ; \mathbf{z})
$$

where 1 denotes the vector in $\Re^{I}$ each of whose components is equal to 1 . Note once again how $\mu(p, \mathbf{m} ; \mathbf{z})$ must increase whenever $V(p, \mathbf{m} ; \mathbf{z})$ does.

In the special case when all the exogenous variables $(p, \mathbf{m}, \mathbf{z})$ happen to assume their reference values $\left(p^{R}, \mathbf{m}^{R}, \mathbf{z}^{R}\right)$, then $\mu\left(p^{R}, \mathbf{m}^{R} ; \mathbf{z}^{R}\right)$ reduces to zero. But when only the variables $(p, \mathbf{z})$ are at their reference values $\left(p^{R}, \mathbf{z}^{\mathbf{R}}\right)$, whereas the income distribution $\mathbf{m}$ has departed from its reference value $\mathbf{m}^{R}$ to $\mathbf{m}^{R}+\sigma \mathbf{1}$ because of some uniform net poll subsidy of size $\sigma$, it must be true, of course, that $\mu\left(p^{R}, \mathbf{m} ; \mathbf{z}^{R}\right)=\sigma$.

\subsection{Uniform Variation}

Consider a change in the exogenous variables $(p, \mathbf{m}, \mathbf{z})$ from initial values $\left(p^{0}, \mathbf{m}^{0}, \mathbf{z}^{0}\right)$ to final values $\left(p^{1}, \mathbf{m}^{1}, \mathbf{z}^{1}\right)$. Given the particular reference prices, incomes and exogenous quantity vectors $\left(p^{R}, \mathbf{m}^{R}, \mathbf{z}^{R}\right)$, a corresponding measure of welfare change is the uniform variation

$$
\mu\left(p^{1}, \mathbf{m}^{1} ; \mathbf{z}^{1}\right)-\mu\left(p^{0}, \mathbf{m}^{0} ; \mathbf{z}^{0}\right)
$$

in uniform money metric social welfare.

As in the case of the money metric measure of variation for a single individual, two particular cases are worth especial attention. The first concerns the uniform compensating variation (or UCV), which arises when $\left(p^{R}, \mathbf{m}^{R}, \mathbf{z}^{R}\right)=\left(p^{1}, \mathbf{m}^{1}, \mathbf{z}^{1}\right)$, so that the final values of the exogenous prices, incomes, and quantities are taken as reference values. Then $\mu\left(p^{1}, \mathbf{m}^{1} ; \mathbf{z}^{1}\right)=\mu\left(p^{R}, \mathbf{m}^{R} ; \mathbf{z}^{R}\right)=0$, and so the measure 
of welfare change (30) becomes $-\mu\left(p^{0}, \mathbf{m}^{0} ; \mathbf{z}^{0}\right)$. Thus UCV must represent the total amount which society is willing to pay, in the form of a uniform poll tax on all individuals, in order to be allowed to make the move from $\left(p^{0}, \mathbf{m}^{0}, \mathbf{z}^{0}\right)$ to $\left(p^{1}, \mathbf{m}^{1}, \mathbf{z}^{1}\right)$. As with the measure of compensating variation for a single individual, for any given fixed final situation $\left(p^{1}, \mathbf{m}^{1}, \mathbf{z}^{1}\right)$, this social measure of uniform compensating variation increases as the status quo $\left(p^{0}, \mathbf{m}^{0} ; \mathbf{z}^{0}\right)$ becomes worse.

The second particular case concerns the uniform equivalent variation (or $\mathrm{UEV})$, which arises when $\left(p^{R}, \mathbf{m}^{R}, \mathbf{z}^{R}\right)=\left(p^{0}, \mathbf{m}^{0}, \mathbf{z}^{0}\right)$, so that the initial values of the exogenous prices, incomes, and quantities are taken as reference values. Then $\mu\left(p^{0}, \mathbf{m}^{0} ; \mathbf{z}^{0}\right)=\mu\left(p^{R}, \mathbf{m}^{R} ; \mathbf{z}^{R}\right)=0$, and so the measure of welfare change $(30)$ reduces to $\mu\left(p^{1}, \mathbf{m}^{1} ; \mathbf{z}^{1}\right)$. In contrast to the uniform compensating variation, the uniform equivalent variation is higher for better changes from an existing status quo. Obviously UEV is itself a welfare indicator. In fact UEV must represent the total amount which the society is willing to be receive, in the form of a uniform poll subsidy on all individuals, in order to avoid making the move from $\left(p^{0}, \mathbf{m}^{0}, \mathbf{z}^{0}\right)$ to $\left(p^{1}, \mathbf{m}^{1}, \mathbf{z}^{1}\right)$.

\subsection{Small Changes}

Having defined uniform equivalent variation and related measures of social welfare change, it is important to know how to calculate them when neither individuals' indirect utility functions nor the indirect social welfare function are known. Instead it is assumed that only individuals' vector demand functions $x_{i}\left(p, m_{i} ; z_{i}\right)(i \in I)$ for those goods with exogenous prices and endogenous quantities are known, as well as the vector willingness to pay functions $w_{i}\left(p, m_{i} ; z_{i}\right)$ $(i \in I)$ for those goods with exogenous quantities and endogenous prices. Obviously, some information about the relative marginal utilities of income for different individuals will also be necessary. Accordingly, let $\beta_{i}(p, \mathbf{m} ; \mathbf{z})$ denote the partial derivative $V_{m_{i}}^{\prime}(p, \mathbf{m} ; \mathbf{z}):=\frac{\partial V_{i}}{\partial m_{i}}(p, \mathbf{m} ; \mathbf{z})$, which is just the marginal social welfare of individual $i$ 's income. This, of course, cannot be observed, since it is not even uniquely defined - it can vary whenever a different indirect social welfare function 
$V(p, \mathbf{m}, \mathbf{z})$ is chosen which represents the same ethical preferences. It will be assumed, however, that all the marginal rates of substitution $\beta_{i}(p, \mathbf{m}, \mathbf{z}) / \beta_{i^{\prime}}(p, \mathbf{m}, \mathbf{z})$ between the income levels of different pairs of individuals $i$ and $i^{\prime}$ are known and are mutually consistent. This is then sufficient information to determine the normalized marginal social welfare

$$
\omega_{i}(p, \mathbf{m} ; \mathbf{z}):=\frac{\beta_{i}(p, \mathbf{m} ; \mathbf{z})}{\sum_{j \in I} \beta_{j}(p, \mathbf{m} ; \mathbf{z})}
$$

of each individual $i$ 's income. It is these ratios which will appear in the formulae to be derived below.

To find the effect of a small change upon the uniform money metric measure of social welfare, take the total differential of (29) while holding the reference situation $\left(p^{R}, \mathbf{m}^{\mathbf{R}}, \mathbf{z}^{\mathbf{R}}\right)$ fixed. Using Roy's identity (2) and also (3), the result is

$$
\begin{aligned}
& \sum_{i \in I} \beta_{i}\left(p^{R}, \mathbf{m}^{R}+\mu(p, \mathbf{m} ; \mathbf{z}) \mathbf{1} ; \mathbf{z}^{R}\right) d \mu \\
= & \sum_{i \in I} \beta_{i}(p, \mathbf{m} ; \mathbf{z})\left[d m_{i}-d p \cdot x_{i}\left(p, m_{i} ; z_{i}\right)+w_{i}\left(p, m_{i} ; z_{i}\right) \cdot d z_{i}\right] .
\end{aligned}
$$

In the special case when $(p, \mathbf{m}, \mathbf{z})$ is the reference situation $\left(p^{R}, \mathbf{m}^{\mathbf{R}}, \mathbf{z}^{\mathbf{R}}\right)$ and so $\mu(p, \mathbf{m}, \mathbf{z})=0,(31)$ implies that (32) reduces to the familiar form

$$
d \mu=\sum_{i \in I} \omega_{i}(p, \mathbf{m} ; \mathbf{z})\left[d m_{i}-d p \cdot x_{i}\left(p, m_{i} ; z_{i}\right)+w_{i}\left(p, m_{i} ; z_{i}\right) \cdot d z_{i}\right] .
$$

For comparison purposes, it is instructive to consider how the total money metric indirect utility function $\Psi(p, \mathbf{m} ; \mathbf{z})$ of Section 3.3 responds to small changes. The relevant total differential of (28) is

$$
\begin{aligned}
& d V^{*}\left(p^{R}, \Psi(p, \mathbf{m} ; \mathbf{z}) ; \mathbf{z}^{R}\right)=V_{M}^{* \prime} d \Psi \\
= & d V(p, \mathbf{m} ; \mathbf{z})=\sum_{i \in I} \beta_{i}(p, \mathbf{m} ; \mathbf{z})\left[d m_{i}-d p \cdot x_{i}\left(p, m_{i} ; z_{i}\right)+w_{i}\left(p, m_{i} ; z_{i}\right) \cdot d z_{i}\right] .
\end{aligned}
$$

From this it follows that

$$
\begin{aligned}
d \Psi & =\frac{\sum_{i \in I} \beta_{i}(p, \mathbf{m} ; \mathbf{z})\left[d m_{i}-d p \cdot x_{i}\left(p, m_{i} ; z_{i}\right)+w_{i}\left(p, m_{i} ; z_{i}\right) \cdot d z_{i}\right]}{V_{M}^{* \prime}\left(p^{R}, \Psi(p, \mathbf{m} ; \mathbf{z}) ; \mathbf{z}^{R}\right)} \\
& =\theta \sum_{i \in I} \omega_{i}(p, \mathbf{m} ; \mathbf{z})\left[d m_{i}-d p \cdot x_{i}\left(p, m_{i} ; z_{i}\right)+w_{i}\left(p, m_{i} ; z_{i}\right) \cdot d z_{i}\right]
\end{aligned}
$$


where

$$
\theta:=\frac{\sum_{j \in I} \beta_{j}(p, \mathbf{m} ; \mathbf{z})}{V_{M}^{* \prime}\left(p^{R}, \Psi(p, \mathbf{m} ; \mathbf{z}) ; \mathbf{z}^{R}\right)} .
$$

Even in the special case when $(p, \mathbf{z})$ is the reference situation $\left(p^{R}, \mathbf{z}^{\mathbf{R}}\right),(35)$ does not generally reduce to (33) but maintains an extra factor

$$
\theta^{R}:=\frac{\sum_{j \in I} \beta_{j}\left(p^{R}, \mathbf{m} ; \mathbf{z}^{R}\right)}{V_{M}^{* \prime}\left(p^{R}, \Psi\left(p^{R}, \mathbf{m} ; \mathbf{z}^{R}\right) ; \mathbf{z}^{R}\right)} .
$$

The numerator of (37) is the marginal social welfare from giving each individual one unit of extra income in the situation $\left(p^{R}, \mathbf{m}, \mathbf{z}^{R}\right)$, where the income distribution may be far from optimal. The denominator is the marginal social welfare of extra total income when income is being distributed optimally. Generally, $\theta^{R} \neq 1$, and in fact $\theta^{R}$ is quite awkward to calculate.

\subsection{A Path Differential Equation}

As in the case of individual money metric measures of utility, it will be sufficient to know how to find the uniform money metric measure of social welfare $\mu(\bar{p}, \overline{\mathbf{m}} ; \overline{\mathbf{z}})$ for any point $(\bar{p}, \overline{\mathbf{m}}, \overline{\mathbf{z}})$, and with respect to an arbitrary reference point $\left(p^{R}, \mathbf{m}^{R}, \mathbf{z}^{R}\right)$. So let $(p(t), \mathbf{m}(t), \mathbf{z}(t))(0 \leq t \leq 1)$ be any continuously differentiable path, parametrized by the real variable $t$, whose two endpoints are respectively $(p(0), \mathbf{m}(0), \mathbf{z}(0))=(\bar{p}, \overline{\mathbf{m}}, \overline{\mathbf{z}})$ and $(p(1), \mathbf{m}(1), \mathbf{z}(1))=\left(p^{R}, \mathbf{m}^{R}, \mathbf{z}^{R}\right)$. For example, one could take the line segment joining $(\bar{p}, \overline{\mathbf{m}}, \overline{\mathbf{z}})$ to $\left(p^{R}, \mathbf{m}^{R}, \mathbf{z}^{R}\right)$, which has $p(t)=\bar{p}+t\left(p^{R}-\bar{p}\right)$ and, for each individual $i \in I$, both $m_{i}(t)=\bar{m}_{i}+t\left(\bar{m}_{i}^{R}-\bar{m}_{i}\right)$ and $z_{i}(t)=\bar{z}_{i}+t\left(\bar{z}_{i}^{R}-\bar{z}_{i}\right)$. But other paths are equally valid and could be chosen instead if they happen to be easier to work with.

A uniform income compensation function $\mu(t)(0 \leq t \leq 1)$ will now be constructed in order to satisfy the equation

$$
V(p(t), \mathbf{m}(t)+\mu(t) \mathbf{1} ; \mathbf{z}(t))=V(\bar{p}, \overline{\mathbf{m}} ; \overline{\mathbf{z}})
$$

all along such a path. Then, when $t=0$ and so $(p(0), \mathbf{m}(0) ; \mathbf{z}(0))=(\bar{p}, \overline{\mathbf{m}}, \overline{\mathbf{z}})$, it follows that $\mu(0)=0$. But, when $t=1$ and so $(p(t), \mathbf{m}(t) ; \mathbf{z}(t))=\left(p^{R}, \mathbf{m}^{R} ; \mathbf{z}^{R}\right)$, 
one will have $V\left(p^{R}, \mathbf{m}^{R}+\mu(1) 1 ; \mathbf{z}^{R}\right)=V(\bar{p}, \overline{\mathbf{m}}, \overline{\mathbf{z}})$. This implies that $\mu(1)$ is the required uniform money metric measure of social welfare.

As with the individual money compensation function of Section 2.8 , the construction here will also involve solving an ordinary differential equation. Note first how, because of the Paretian form of the indirect social welfare function (25), and because both Roy's identity (2) and (3) are satisfied by each individual's indirect utility and demand functions, it must be true that the partial gradient vectors of $V$ with respect to the price vector and with respect to each individual's quantity vector will satisfy

$$
\begin{aligned}
V_{p}^{\prime}(p, \mathbf{m} ; \mathbf{z}) & =-\sum_{i \in I} \beta_{i}(p, \mathbf{m} ; \mathbf{z}) x_{i}\left(p, m_{i} ; z_{i}\right) \\
V_{z_{i}}^{\prime}(p, \mathbf{m} ; \mathbf{z}) & =\beta_{i}(p, \mathbf{m} ; \mathbf{z}) w_{i}\left(p, m_{i} ; z_{i}\right)
\end{aligned}
$$

Then, differentiating (38) totally with respect to $t$ shows that

$$
\sum_{i \in I} \beta_{i}(t)\left[\dot{m}_{i}(t)+\dot{\mu}(t)-\dot{p}(t) \cdot x_{i}(t)+w_{i}(t) \cdot \dot{z}_{i}(t)\right]=0
$$

where, of course, $\dot{p}, \dot{m}_{i}$ and $\dot{z}_{i}$ all denote derivatives with respect to $t$. Also, $\beta_{i}(t)$ has been written as an abbreviation for $\left.\beta_{i}(p(t), \mathbf{m}(t)+\mu(t) \mathbf{1} ; \mathbf{z}(t))\right), x_{i}(t)$ for $x_{i}\left(p(t), m_{i}(t)+\mu(t) ; z_{i}(t)\right)$, and $w_{i}(t)$ for $w_{i}\left(p(t), m_{i}(t)+\mu(t) ; z_{i}(t)\right)$. Since $\sum_{i \in I} \beta_{i}(t)$ is always positive under the assumptions made above, and using the definition of $\omega_{i}$ in (31) as the normalized marginal social welfare of individual $i$ 's income, this equation then reduces to the ordinary differential equation

$$
\dot{\mu}=\sum_{i \in I} \omega_{i}\left[\dot{p} \cdot x_{i}\left(p, m_{i}+\mu ; z_{i}\right)-\dot{m}_{i}-w_{i}\left(p, m_{i}+\mu ; z_{i}\right) \cdot \dot{z}_{i}\right]
$$

in the single variable $\mu(t)$, where all the time arguments have been suppressed. The initial condition, of course, is $\mu(0)=0$. 


\subsection{Integrability and Path Independence}

As in the case of the individual money metric measure of utility, notice that, whenever the demand and willingness to pay functions are derived from preferences satisfying assumptions (A.1-A.5) above, and the normalized welfare weights $\omega_{i}$ are derived from an explicit social welfare function, this differential equation must have a unique solution for $\mu(1)$ which is independent of how the continuous path $(p(t), \mathbf{m}(t), \mathbf{z}(t))(0 \leq t \leq 1)$ from $(\bar{p}, \overline{\mathbf{m}}, \overline{\mathbf{z}})$ to $\left(p^{R}, \mathbf{m}^{R}, \mathbf{z}^{R}\right)$ is chosen - namely, the only possible solution for $\mu(1)$ must be the desired uniform money metric measure of social welfare $\mu(\bar{p}, \overline{\mathbf{m}} ; \overline{\mathbf{z}})$.

It is more interesting, however, as was the case with individual measures of welfare, to know what conditions the demand functions $x_{i}\left(p, m_{i} ; z_{i}\right)$, willingness to pay functions $w_{i}\left(p, m_{i} ; z_{i}\right)$, and normalized marginal utility functions $\omega_{i}(p, \mathbf{m} ; \mathbf{z})$ must jointly satisfy in order to ensure that they do all correspond to preference orderings for each consumer which are then aggregated by means of some Paretian social welfare ordering. Obviously, we shall have to insist on the conditions of Section 2.9 under which individual preference orderings exist. Thus, our concern here is really just with the extra conditions which must be imposed upon the functions $\omega_{i}(p, \mathbf{m} ; \mathbf{z})$.

The argument which will be used here differs from that in Section 2.9 for the case of a single individual because, whereas the functions $x_{i}\left(p, m_{i} ; z_{i}\right)$ and $w_{i}\left(p, m_{i} ; z_{i}\right)$ describe the utility-maximing behaviour and willingness to pay of consumer $i$, the functions $\omega_{i}(p, \mathbf{m} ; \mathbf{z})$ represent the value judgements of whoever is constructing the social welfare measures. However, as with the earlier individual money metric, in order that (41) can be solved uniquely for $\mu(t)$ along any path from $(\bar{p}, \overline{\mathbf{m}}, \overline{\mathbf{z}})$ to the reference point $\left(p^{R}, \mathbf{m}^{R}, \mathbf{z}^{R}\right)$, with the initial condition $\mu(0)=$ 0 always being satisfied, there must be a general income compensation function $\mu(p, \mathbf{m} ; \mathbf{z})$ which satisfies the more general version

$$
V(p, \mathbf{m}+\mu(p, \mathbf{m} ; \mathbf{z}) \mathbf{1} ; \mathbf{z})=V(\bar{p}, \overline{\mathbf{m}} ; \overline{\mathbf{z}})
$$

of (38). The difference arises because we already know that there exists a money 
metric utility function $\left.\psi_{i}\left(p, m_{i} ; z_{i}\right) ; z_{i}^{R}\right)$ satisfying a version of (5) appropriate to each individual $i \in I$, namely

$$
v_{i}\left(p^{R}, \psi_{i}\left(p, m_{i} ; z_{i}\right) ; z_{i}^{R}\right) \equiv v_{i}\left(p, m_{i} ; z_{i}\right)
$$

Then, because the indirect social welfare function has a Paretian form (25), there must exist some stricly increasing function $\Omega^{*}$ defined on $\Re^{I}$ with the property that

$$
V(p, \mathbf{m} ; \mathbf{z}) \equiv \Omega^{*}\left(\left\langle\psi_{i}\left(p, m_{i} ; z_{i}\right)\right\rangle_{i \in I}\right) .
$$

The obvious condition to be imposed now is that the normalized marginal utility functions $\omega_{i}(p, \mathbf{m} ; \mathbf{z})$ can be derived from such an explicit social welfare function. That is, it must be true that

$$
\omega_{i}(p, \mathbf{m} ; \mathbf{z}) \equiv \frac{\partial \Omega^{*}}{\partial \psi_{i}} \frac{\partial \psi_{i}}{\partial m_{i}} / \sum_{j \in I} \frac{\partial \Omega^{*}}{\partial \psi_{j}} \frac{\partial \psi_{j}}{\partial m_{j}} .
$$

This is the required condition on the welfare weights $\omega_{i}(p, \mathbf{m} ; \mathbf{z})$ which ensures both integrability and path independence of any possible solution to (42).

\subsection{Social Catastrophes}

As with the individual measures of money metric utility, it is important to consider also when the uniform money metric social welfare function is well defined. To this end, define

$$
\underline{m}_{i}^{R}:=\min _{x}\left\{p^{R} \cdot x \mid\left(x, z_{i}^{R}\right) \in F_{i}\right\}
$$

as individual $i$ 's minimum income level consistent with physical feasibility for him alone when the exogenous price and quantity vectors are at their reference levels. Then let

$$
\bar{\tau}:=\max _{i \in I}\left\{m_{i}^{R}-\underline{m}_{i}^{R}\right\}
$$

be the maximum uniform poll tax which can be levied in the reference situation $\left(p^{R}, \mathbf{m}^{R}, \mathbf{z}^{R}\right)$ without forcing anybody outside their physically feasible set. Also, let

$$
\underline{V}^{R}:=V\left(p^{R}, \mathbf{m}^{R}-\bar{\tau} \mathbf{1} ; \mathbf{z}^{R}\right)
$$


be the corresponding minimum level of social welfare which can be achieved by making the poll tax as large as possible. Finally, let

$$
\bar{V}^{R}:=\sup _{\mu}\left\{V\left(p^{R}, \mathbf{m}^{R}+\mu 1 ; \mathbf{z}^{R}\right)\right\}
$$

be the corresponding supremum level of social welfare from an indefinitely large uniform poll subsidy. The value of $\bar{V}^{R}$, of course, could be $+\infty$. Then, as in the similar case of individual money metric utility considered in the previous section, it is obvious that the measure $\mu(p, \mathbf{m} ; \mathbf{z})$ of uniform money metric social welfare is well defined for all $(p, \mathbf{m}, \mathbf{z})$ satisfying $\underline{V}^{R} \leq V(p, \mathbf{m} ; \mathbf{z})<\bar{V}^{R}$, but not outside this range.

When $V(p, \mathbf{m} ; \mathbf{z})<\underline{V}^{R}$, the situation $(p, \mathbf{m} ; \mathbf{z})$ is so bad that some individuals cannot afford to pay the uniform poll tax which would be needed to reduce social welfare this much. This is a "social catastrophe," in effect. But even so one could still have $v_{i}\left(p, m_{i} ; z_{i}\right)$ slightly larger than $\underline{v}_{i}^{R}:=v_{i}\left(p^{R}, \underline{m}_{i}^{R} ; z_{i}^{R}\right)$ for all individuals $i \in I$, implying that a social catastrophe need not be any person's individual catastrophe. For suppose that $m_{i}^{R}$ is very much larger than $\underline{m}_{i}^{R}$ for a large proportion of individuals who are accordingly somewhat rich, yet $m_{i}^{R}$ is only very slightly larger than $\underline{m}_{i}^{R}$ for the others who are accordingly rather poor. Then, if social welfare has to be reduced by means of a uniform poll tax, there can easily be a limit to how low social welfare can fall because of the limit on how much poll tax the poorer individuals can be forced to pay. In this sense, social catastrophes can arise purely because the distribution of income implies very unequal abilities to pay taxes.

The other problematic case occurs when the situation $(p, \mathbf{m} ; \mathbf{z})$ is so good that $V(p, \mathbf{m} ; \mathbf{z}) \geq \bar{V}^{R} \geq V\left(p^{R}, \mathbf{m}^{R}+\mu \mathbf{1} ; \mathbf{z}^{R}\right)$ for all finite scalars $\mu$, no matter how large. Because of the Paretian form of the social welfare function, this can only occur if there exists at least one individual $i \in I$ for whom $v_{i}\left(p, m_{i} ; z_{i}\right) \geq \bar{v}_{i}^{R}:=$ $\sup _{m} v_{i}\left(p^{R}, m ; z_{i}^{R}\right)$. The corresponding possibility for individuals was discussed in Section 2.9 , and nothing more needs to be added here. 


\section{Conclusions and Remaining Problems}

\subsection{Summary}

Methods of constructing money metric measures of individual and social welfare have been presented. They work even when some important aspects of the environment are subject to change, though with a few important exceptions which can arise in connection with "catastrophes" for which the willingness to pay to avoid them is too large to be properly defined. For individual welfare, the standard money metric was extended in a rather obvious way to deal with exogenous quantity (or environmental quality) variables which affect well-being. In the case of social welfare, however, a new "uniform money metric" was eventually proposed. This is based on the amount of a uniform poll tax or subsidy which would produce an equivalent effect on the well-being of society as a whole, according to some specific social welfare function which respects individuals' preferences.

\subsection{Alternatives to Uniform Poll Taxes and Subsidies}

Much of the existing literature concerned with money metric measures of social welfare relies on comparing existing situations with what would be possible in the presence of optimal lump-sum transfers. This makes the measures hard to interpret, since they relate to monetary gains which could only be realized through policies which, because of incentive compatibility problems, are probably totally impractical. As an alternative, uniform poll taxes and subsidies are certainly much more realistic instruments of policy. The money metric measures which are based upon them therefore have the merit of giving us some idea of how large a welfare gain is really possible with a policy that could just possibly be carried out in practice. Yet uniform poll taxes or subsidies may be not much less impractical than lump-sum transfers. Nor are they likely to be desirable even if they can actually be put into effect.

Really, the policy measure to be used in measuring welfare should be one that is actually quite likely to be carried out in the event that the economy suddenly 
experiences a windfall gain or loss of some kind. Changes in the rate of income taxation seem much more plausible, but would not generate money metric measures. A general alternative which would be a monetary measure could be constructed as follows: first specify a policy rule which determines, as a function of the size of any sudden windfall gain or loss, what tax and other policy changes it is believed that the government would want to carry out in response to a gain or loss of that magnitude. Also specify a reference situation which is believed to be what will happen in the event of a gain or loss of zero. Then, given the level of social welfare in any other situation, find the size of that gain or loss to which the government's policy response would generate exactly the same level of social welfare. This is a much broader class of money metric measures of social welfare than the very specific uniform measure considered here. For the latter presumes, in effect, that the government will distribute any gain through a uniform poll subsidy, and meet any loss with the revenue from a uniform poll tax.

\subsection{Time and Uncertainty}

At first it may appear that this paper has considered exclusively static models of the economy and the environment. If true, this would obviously be a very serious limitation, especially as environmental damage is often very long-lasting. Yet in fact the same ideas could fairly easily be adapted to intertemporal models as well - cf. the discussion in Hammond (1990b) of economies with dated contingent commodities and consumers, and the resulting dated contingent money metric measures of welfare in each period. 


\subsection{Data}

Like my other work in this area, this paper has been purely theoretical. As argued in Hammond (1990a), before making the compromises which are necessary because data are often very limited or unreliable, I think it is important to understand just how welfare could be measured in an ideal situation with unlimited data. Accordingly this paper presumes unlimited knowledge of all individuals' demand, supply and willingness to pay functions. In order to find the welfare effect of any actual policy change, moreover, it presumes that the resulting comparative static effects upon the prices and quantities which affect consumers are also all known with certainty. It must be admitted that there is an enormous gulf between this extreme hypothesis and what is actually known about real economies. Much work still remains to be done even on the theory of estimating welfare measures which are based on the kind of highly imperfect data which are all that applied economists usually have available. This paper has tried to set out the kind of measure which applied economists are likely to find themselves wanting to estimate.

\section{References}

A.B. AtKinson (1970), "On the Measurement of Inequality," Journal of Economic Theory, 2: 244-63.

P.J. HAMmond (1979), "Straightforward Individual Incentive Compatibility in Large Economies," Review of Economic Studies, 46: 263-282.

P.J. Hammond (1984), "Approximate Measures of Social Welfare and the Size of Tax Reform," in Beiträge zur neueren Steuertheorie edited by D. Bös, M. Rose, and C. Seidl (Berlin: Springer-Verlag), pp. 95-115.

P.J. Hammond (1987), "Markets as Constraints: Multilateral Incentive Compatibility in Continuum Economies," Review of Economic Studies, 54: 399-412. 
P.J. HAmmond (1988), "Principles for Evaluating Public Sector Projects," in Surveys in Public Sector Economics edited by P. Hare (Oxford: Basil Backwell), ch. 2, pp. 15-44.

P.J. Hammond (1990a), "Theoretical Progress in Public Economics: A Provocative Assessment," Oxford Economic Papers, 42: 6-33.

P.J. HAmmond (1990b), "Intertemporal Objectives," European University Institute, Economics Working Paper No. 90/???; forthcoming in The Handbook of Natural Resources and Energy Economics, Vol. III.

J.A. Hausman (1981), "Exact Consumer Surplus and Deadweight Loss," American Economic Review, 71: 662-676.

J.R. Hicks (1939), "The Foundations of Welfare Economics," Economic Journal, 49: 696-712.

J.R. Hicks (1940), "The Valuation of the Social Income," Economica, 7: 105-124.

J.R. Hicks (1981), Wealth and Welfare. Cambridge, Mass: Harvard University Press.

M.W. Jones-LeE (1974), "The Value of Changes in the Probability of Death or Injury," Journal of Political Economy, 82: 835-849.

M.W. Jones-Lee (1976), The Value of Life: An Economic Analysis. London: Martin Robertson; and Chicago: University of Chicago Press.

D.W. Jorgenson (1989), "Aggregate Consumer Behavior and the Measurement of Social Welfare," Harvard Institute of Economics Research, Discussion Paper No. 1446; forthcoming in Econometrica.

D.W. Jorgenson And D.T. Slesnick (1989), "Redistributional Policy and the Measurement of Poverty," in Research on Economic Inequality, Vol. 1 edited by D. Slottje (Greenwich: JAI Press), pp. 1-48. 
D.W. Jorgenson And D.T. Slesnick (1990), "Inequality and the Standard of Living," Journal of Econometrics, 43: 103-120.

R.A. Pollak (1981), "The Social Cost of Living Index," Journal of Public Economics, 15: 311-336.

K. Roberts (1984), "The Theoretical Limits to Redistribution," Review of Economic Studies, 51: 177-195.

Y.O. Vartia (1983), "Efficient Methods of Measuring Welfare Change and Compensated Income in Terms of Demand Functions," Econometrica, 51: 79-98. 


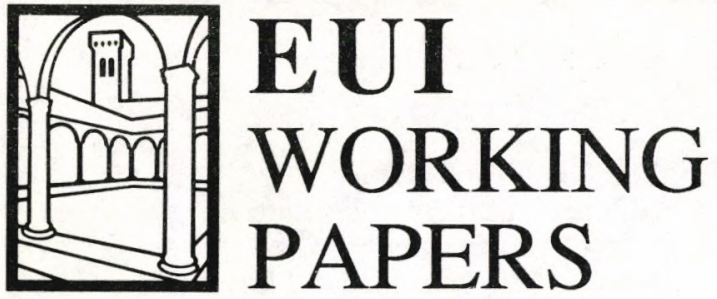

EUI Working Papers are published and distributed by the European University Institute, Florence

Copies can be obtained free of charge - depending on the availability of stocks - from:

The Publications Officer

European University Institute

Badia Fiesolana

I-50016 San Domenico di Fiesole (FI)

Italy

Please use order form overleaf 


\section{Publications of the European University Institute}

To

The Publications Officer

European University Institute

Badia Fiesolana

I-50016 San Domenico di Fiesole (FI)

Italy

From

Name

Address

$\square$ Please send me a complete list of EUI Working Papers

$\square$ Please send me a complete list of EUI book publications

$\square$ Please send me the EUI brochure Academic Year 1990/91

Please send me the following EUI Working Paper(s):

No, Author

Title:

No, Author

Title:

No, Author

Title:

No, Author

Title:

Date

Signature 


\section{Working Papers of the Department of Economics Published since 1989}

\section{$89 / 370$}

B. BENSAID/ R.J. GARY-BOBO/

S. FEDERBUSCH

The Strategic Aspects of Profit Sharing in the Industry

$89 / 374$

Francisco $S$. TORRES

Small Countries and Exogenous Policy Shocks

$89 / 375$

Renzo DAVIDDI

Rouble Convertibility: A Realistic Target

\section{$89 / 377$}

Elettra AGLIARDI

On the Robustness of Contestability Theory

\section{$89 / 378$}

Stephen MARTIN

The Welfare Consequences of Transaction Costs in Financial Markets

\section{$89 / 381$}

Susan SENIOR NELLO

Recent Developments in Relations Between the $\mathrm{EC}$ and Eastern Europe

\section{$89 / 382$}

Jean GABSZEWICZ/ Paolo GARELLA/

Charles NOLLET

Spatial Price Competition With Uninformed Buyers

\section{$89 / 383$}

Benedetto GUI

Beneficiary and Dominant Roles in

Organizations: The Case of Nonprofits

\section{$89 / 384$}

Agustín MARAVALL/ Daniel PEÑA Missing Observations, Additive Outliers and Inverse Autocorrelation Function

\section{$89 / 385$}

Stephen MARTIN

Product Differentiation and Market Performance in Oligopoly

\section{$89 / 386$}

Dalia MARIN

Is the Export-Led Growth Hypothesis Valid for Industrialized Countries?
89/387

Stephen MARTIN

Modeling Oligopolistic Interaction

$89 / 388$

Jean-Claude CHOURAQUI

The Conduct of Monetary Policy: What have we Learned From Recent Experience

\section{$89 / 390$}

Corrado BENASSI

Imperfect Information and Financial Markets: A General Equilibrium Model

\section{$89 / 394$}

Serge-Christophe KOLM

Adequacy, Equity and Fundamental Dominance: Unanimous and Comparable Allocations in Rational Social Choice, with Applications to Marriage and Wages

\section{$89 / 395$}

Daniel HEYMANN/ Axel LEIJONHUFVUD

On the Use of Currency Reform in Inflation Stabilization

\section{$89 / 400$}

Robert J. GARY-BOBO

On the Existence of Equilibrium Configurations in a Class of Asymmetric Market Entry Games*

\section{$89 / 402$}

Stephen MARTIN

Direct Foreign Investment in The United States

$89 / 413$

Francisco S. TORRES

Portugal, the EMS and 1992: Stabilization and Liberalization

$89 / 416$

Jörg MAYER

Reserve Switches and Exchange-Rate Variability: The Presumed Inherent Instability of the Multiple Reserve-Currency System

$89 / 417$

José P. ESPERANÇA/ Neil KAY

Foreign Direct Investment and Competition in the Advertising Sector: The Italian Case

\section{$89 / 418$}

Luigi BRIGHI/ Mario FORNI

Aggregation Across Agents in Demand Systems 
$89 / 420$

Corrado BENASSI

A Competitive Model of Credit Intermediation

$89 / 422$

Marcus MILLER/ Mark SALMON

When does Coordination pay?

$89 / 423$

Marcus MILLER/ Mark SALMON/

Alan SUTHERLAND

Time Consistency, Discounting and the Returns to Cooperation

\section{$89 / 424$}

Frank CRITCHLEY/ Paul MARRIOTT/

Mark SALMON

On the Differential Geometry of the Wald Test

with Nonlinear Restrictions

$89 / 425$

Peter J. HAMMOND

On the Impossibility of Perfect Capital Markets

$89 / 426$

Peter J. HAMMOND

Perfected Option Markets in Economies with

Adverse Selection

$89 / 427$

Peter J. HAMMOND

Irreducibility, Resource Relatedncss, and Survival with Individual Non-Convexities

ECO No. $90 / 1^{\circ}$

Tamer BAŞAR and Mark SALMON

Credibility and the Value of Information

Transmission in a Model of Monetary Policy and Inflation

ECO No. $90 / 2$

Horst UNGERER

The EMS - The First Ten Years

Policies - Developments - Evolution

ECO No. 90/3

Peter J. HAMMOND

Interpersonal Comparisons of Utility: Why and how they are and should be made

ECO No. 90/4

Peter J. HAMMOND

A Revelation Principle for (Boundedly) Bayesian Rationalizable Strategies

- Please note: As from January 1990, the EUI Working Papers Series is divided into six subseries, each series will be numbered "individually (e.g. EUI Working Paper LAW No. 90/1).
ECO No. $90 / 5$

Peter J. HAMMOND

Independence of Irrelevant Interpersonal

Comparisons

ECO No. $90 / 6$

Hal R. VARIAN

A Solution to the Problem of Externalities and Public Goods when Agents are Well-Informed

ECO No, $90 / 7$

Hal R. VARIAN

Sequential Provision of Public Goods

ECO No. $90 / 8$

T. BRIANZA, L. PHLIPS and J.F. RICHARD Futures Markets, Speculation and Monopoly Pricing

ECO No. $90 / 9$

Anthony B. ATKINSON/ John

MICKLEWRIGHT

Unemployment Compensation and Labour

Market Transition: A Critical Review

ECO No. $90 / 10$

Peter J. HAMMOND

The Role of Information in Economics

ECO No. 90/11

Nicos M. CHRISTODOULAKIS

Debt Dynamics in a Small Open Economy

ECO No. $90 / 12$

Stephen C. SMITH

On the Economic Rationale for Codetermination Law

ECO No. $90 / 13$

Elettra AGLIARDI

Learning by Doing and Market Structures

ECO No. 90/14

Peter J. HAMMOND

Intertemporal Objectives

ECO No. 90/15

Andrew EVANS/Stephen MARTIN

Socially Acceptable Distortion of Competition: EC Policy on State Aid

ECO No. 90/16

Stephen MARTIN

Fringe Size and Cartel Stability 
ECO No. 90/17

John MICKLEWRIGHT

Why Do Less Than a Quarter of the

Unemployed in Britain Receive Unemployment Insurance?

ECO No. 90/18

Mrudula A. PATEL

Optimal Life Cycle Saving

With Borrowing Constraints:

A Graphical Solution

ECO No. 90/19

Peter J. HAMMOND

Money Metric Measures of Individual and Social

Welfare Allowing for Environmental

Externalities

ECO No. $90 / 20$

Louis PHLIPS/

Ronald M. HARSTADT

Oligopolistic Manipulation of Spot Markets and the Timing of Futures Market Speculation 
